\title{
MEDIUM-TERM ASSESSMENT OF TOTAL KNEE ARTHROPLASTY WITH IMPLANT MADE IN BRAZIL
}

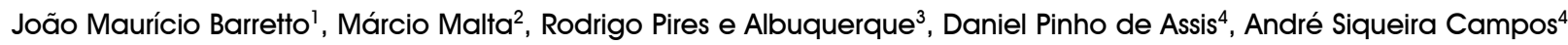

\section{ABSTRACT}

Objective: This study assessed 47 patients who underwent total knee arthroplasty (TKA) with implants manufactured in Brazil, with a mean followup of five years. Methods: This was a retrospective study at Santa Casa de Misericordia Hospital in Rio de Janeiro, from January 1993 to December 2002. The sample comprised 47 patients (44 females and three males) who underwent TKA, totaling 58 knees. The patients' ages ranged from 46 to 83 years. A diagnosis of osteoarthritis or rheumatic disease was confirmed in all the patients. Results: In this investigation, all the patients underwent cemented TKA with preservation of the posterior cruciate ligament. The length of follow-up ranged from 5 to 17 years. The functional assessment criterion used was the one of the Hospital for Special Surgery (HSS), and this yielded an average of 87 points after the operation. The radiographic criterion used was the Knee Society Total Knee Arthroplasty Roentgenographic Evaluation and Scoring System. We had three cases with a radiolucent line without implant loosening, which were asymptomatic from a clinical standpoint. Conclusion: The total knee arthroplasty procedures using an implant made in Brazil were performed by a trained and experienced team. To date, over the clinical follow-up on these patients with knee osteoarthritis or rheumatoid arthritis, the results have been seen to be satisfactory.

Keywords - Knee; Arthroplasty; Retrospective Studies; Knee Prosthesis

\section{INTRODUCTION}

Total knee arthroplasty is a high-complexity surgical procedure that is basically indicated for patients with a diagnosis of primary or secondary knee osteoarthrosis or rheumatic diseases. This surgical procedure has been constantly evolving since its creation. Implants with a more modern design resembling the anatomy of the normal knee as much as possible, together with instruments that are increasingly precise and cause less aggression to soft tissues, have made the surgical indications increasingly comprehensive.

The good results obtained after performing total knee arthroplasty are well-documented in the literature, with regard to both pain relief and maintenance of these results over long-term follow-up ${ }^{(1-6)}$.

The success of the surgical procedure depends on many factors: a surgeon who is familiar with the procedure, good ligament balance, adequate and precise instruments and a good-quality durable implant.

The aim of this study was to evaluate 47 patients who underwent total knee arthroplasty using an implant made in Brazil, with a mean follow-up of five years.

\footnotetext{
1 - Head of the Orthopedics and Traumatology Service, Santa Casa de Misericórdia do Rio de Janeiro, Rio de Janeiro, RJ, Brazil; MSc and PhD in Medicine.

2 - Head of the Orthopedics and Traumatology Service, Fluminense Federal University (UFF), Rio de Janeiro, RJ, Brazil; MSc and PhD in Medicine.

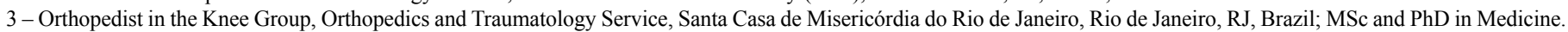

4 - Orthopedist in the Knee Group, Orthopedics and Traumatology Service, Santa Casa de Misericórdia do Rio de Janeiro, Rio de Janeiro, RJ, Brazil.

Work performed at the Orthopedics and Traumatology Service, Santa Casa de Misericórdia do Rio de Janeiro.

Correspondence: Rodrigo Pires e Albuquerque, Av. Henrique Dodsworth 83/105, Copacabana, 22061-030 Rio de Janeiro, RJ. E-mail: rodalbuquerque@ibest.com.br Work received for publication: January 11, 2011; accepted for publication: March 25, 2011 ..
} 


\section{METHODS}

Between January 1993 and December 2002, a retrospective study was conducted at the Knee Outpatient Clinic of Santa Casa de Misericórdia do Rio de Janeiro composed of 47 patients and a total of 58 knees. A diagnosis of osteoarthrosis or rheumatic disease was confirmed in all these patients, who then underwent cemented total primary knee arthroplasty that preserved the posterior cruciate ligament. The prosthesis used was made in Brazil (Baumer S/A, Mogi Mirim, São Paulo, Total Knee Arthroplasty model). The patients' ages ranged from 46 to 83 years, with a mean of 67.3 years. In the study, the patients were divided into two groups according to age group, with a cutoff age of 65 years. A division according to age group was made because arthroplasty in younger patients theoretically has lower durability. The limit of 65 years of age is a parameter that was imposed historically, from the time of the first arthroplasties, as ideal for this type of surgical procedure. Forty-four female patients and three male patients underwent the operation (Figures 1, 2 and 3).

The inclusion criterion for the patients was the presence of knee pain together with anamnesis and physical examination compatible with osteoarthrosis or rheumatic disease, as well as absence of previous surgery on the knee.

Before the operation and after a mean postoperative follow-up of five years, evaluations were made by a single physician who was a member of the Brazilian Society of Knee Surgery and had a doctorate in orthopedics. The protocol used was the knee osteoarthrosis protocol of the Hospital for Special Surgery (HSS) $)^{(7)}$, with clinical measurements of the angle of the anatomical axis of the lower limb under assessment and radiographs of the knee while standing on both feet, in anteroposterior and lateral views ${ }^{(8)}$. In the radiographic analysis, implant loosening was evaluated by means of the criteria used in the Knee Society Total Knee Arthroplasty Roentgenographic Evaluation and Scoring System ${ }^{(9)}$. Six variables were evaluated in the HSS knee protocol: pain, function, range of motion, muscle strength, deformity in flexion and instability. Points were deducted if crutches or a walking stick were used, loss of active extension of the knee was presented, or there was varus and valgus instability. The maximum score was 100 points, categorized thus: 85 points or more was considered to be excellent; 70 to 84 , good; 60 to 69 , fair; and 60 or less, unsatisfactory.

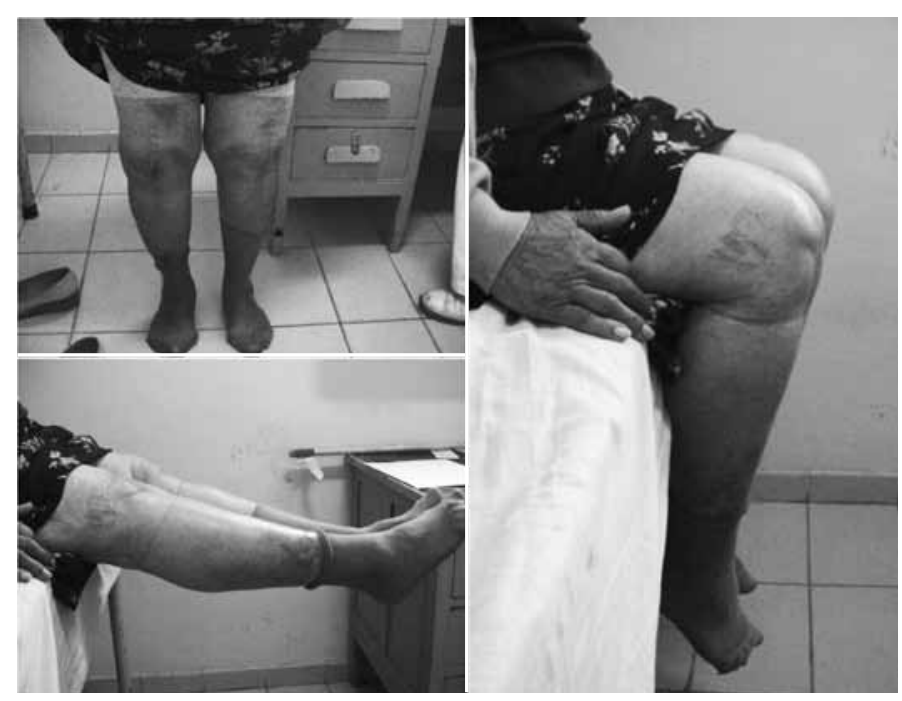

Figure 1 - Postoperative clinical evaluation (15 years, right knee; and 17 years, left knee, respectively).
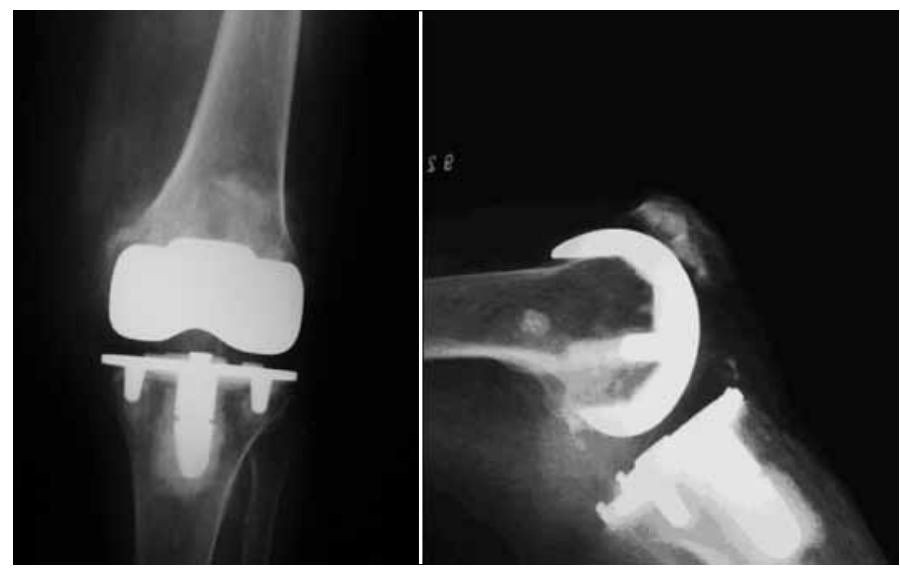

Figure 2 - Postoperative radiograph on right knee (15 years of follow-up).

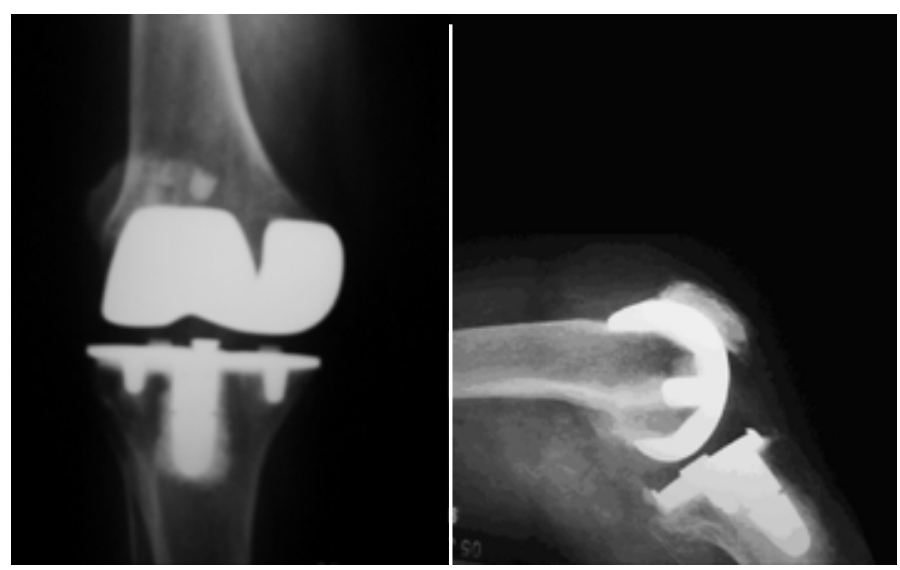

Figure 3 - Postoperative radiograph on left knee (17 years of follow-up).

All the patients underwent surgery performed by the same medical team. In all cases, a pneumatic tourniquet, anterior access to the knee, medial parapatellar arthrotomy and patellar replacement were used. 
Prevention of thromboembolism was achieved through general measures: compressive bandaging, elevation of the lower limbs, partial weight-bearing on the second postoperative day and early physiotherapy.

The statistical analysis was composed of two methods. In an analysis to investigate whether there was any significant variation in HSS score (points) from before to after the operation, the Wilcoxon test was used. To investigate whether there was any significant difference in the delta (absolute and relative) of the HSS score between the subgroups according to the age groups, the Mann-Whitney test was applied.

Nonparametric methods were used, since the HSS score did not present normal distribution (Gaussian distribution). The criterion for determining significance was the level of $5 \%$. The statistical analysis was processed using the software of the SAS ${ }^{\circledR}$ statistical system.

\section{RESULTS}

This analysis had the aim of outlining a general profile of the 58 knees under examination. Table 1 shows the mean, standard deviation (SD), median, minimum and maximum for the patients' ages and their length of follow-up.

Table 2 shows the mean, standard deviation (SD), median, minimum and maximum for the HSS scores before and after the operation, the corresponding absolute change (delta) and relative change (delta $\%$ ) and the respective descriptive levels ( $p$ values) of the Wilcoxon signed rank test. The absolute change in HSS score from before to after the operation was given by the formula: Delta HSS = (postoperative HSS score - preoperative HSS score). The relative change (\%) in HSS score from before to after the operation was: Relative delta HSS $(\%)=$ (postoperative HSS score - preoperative HSS score) / preoperative HSS $\mathrm{x} 100$.

In this study, we observed that there was a significant increase in mean HSS score after the surgery, of 27.7 points $(p=0.0001)$, which corresponded to a mean of $52.8 \%(\mathrm{p}=0.0001)$, as shown in Figure 4.

Tables 3 and 4 show the mean, standard deviation or standard error (SD or SE), median, minimum and maximum HSS scores before and after the operation, the corresponding absolute change (delta) and relative change (delta \%) and the respective descriptive level ( $p$ value) of the Wilcoxon signed rank test, stratified according to age group ( $>65$ and $\leq 65$ years).
Table 1 - Description of the numerical variables.

\begin{tabular}{c|c|c|c|c|c|c}
\hline Variable & $\mathbf{n}$ & Mean & SD & Median & Minimum & Maximum \\
\hline Age (years) & 58 & 67.3 & 7.6 & 67 & 46 & 83 \\
\hline Follow-up (years) & 58 & 7.4 & 2.4 & 7 & 5 & 17 \\
\hline
\end{tabular}

SD: standard deviation.

Source: Santa Casa, 2010.

Table 2 - Analysis on postoperative HSS score.

\begin{tabular}{c|c|c|c|c|c|c|c}
\hline HSS SCORE & $\mathbf{n}$ & Mean & SD/SE & Median & Minimum & Maximum & value \\
\hline $\begin{array}{c}\text { Before } \\
\text { operation } \\
\text { (points) }\end{array}$ & 58 & 59.3 & 11.1 & 60 & 33 & 81 & \\
\hline $\begin{array}{c}\text { After operation } \\
\text { (points) }\end{array}$ & 58 & 87.0 & 5.4 & 88 & 71 & 96 & \\
\hline $\begin{array}{c}\text { Delta HSS } \\
\text { (points) }\end{array}$ & 58 & 27.7 & 1.6 & 29 & 7 & 60 & 0.0001 \\
\hline $\begin{array}{c}\text { Relative delta } \\
\text { HSS (\%) }\end{array}$ & 58 & 52.8 & 4.7 & 48.4 & 9.1 & 181.8 & 0.0001 \\
\hline
\end{tabular}

SD: standard deviation; SE: standard error, only for the deltas. Source: Santa Casa, 2010

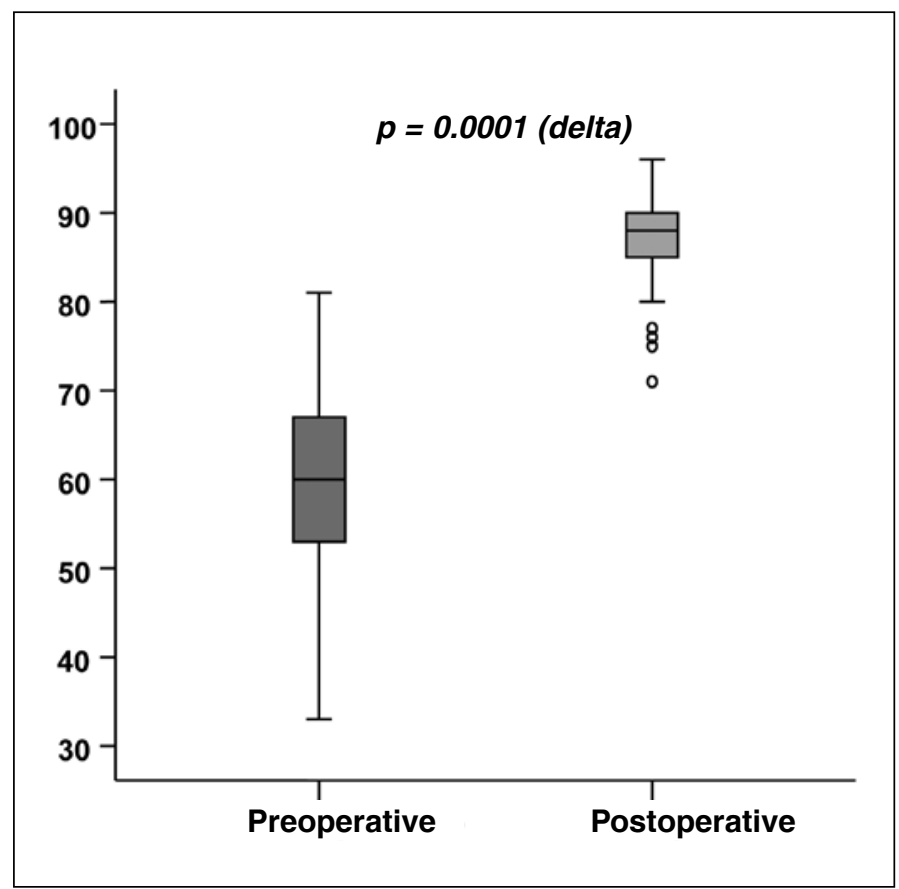

Figure 4 - Preoperative and postoperative HSS scores

In our analysis, we observed that there was a significant increase in HSS score after surgery, in the subgroup $>65$ years of age, with a mean of 29.1 points $(p=0.0001)$, which corresponded to a mean of $55.9 \%$ $(\mathrm{p}=0.0001)$. 
Table 3 - Analysis on postoperative HSS score, stratified for age $>65$ years.

\begin{tabular}{c|c|c|c|c|c|c|c}
\hline HSS SCORE & $\mathbf{n}$ & Mean & SD/SE & Median & Minimum & Maximum & p value \\
\hline $\begin{array}{c}\text { Before } \\
\text { operation } \\
\text { (points) }\end{array}$ & 38 & 58.4 & 10.6 & 59 & 33 & 80 & \\
\hline $\begin{array}{c}\text { After operation } \\
\text { (points) }\end{array}$ & 38 & 87.5 & 5.3 & 88.5 & 71 & 96 & 0.0001 \\
\hline $\begin{array}{c}\text { Delta HSS } \\
\text { (points) }\end{array}$ & 38 & 29.1 & 2.0 & 29 & 7 & 60 & 0.0001 \\
\hline $\begin{array}{c}\text { Relative delta } \\
\text { HSS (\%) }\end{array}$ & 38 & 55.9 & 6.0 & 49.2 & 9.1 & 181.8 & \\
\hline
\end{tabular}

SD: standard deviation; SE: standard error, only for the deltas.

Source: Santa Casa, 2010.

Table 4 - Analysis on postoperative HSS score, stratified for age $\leq 65$ years.

\begin{tabular}{c|c|c|c|c|c|c|c}
\hline HSS SCORE & $\mathbf{n}$ & Mean & SD/SE & Median & Minimum & Maximum & p value \\
\hline $\begin{array}{c}\text { Before } \\
\text { operation } \\
\text { (points) }\end{array}$ & 20 & 61.0 & 12.1 & 60 & 37 & 81 & \\
\hline $\begin{array}{c}\text { After operation } \\
\text { (points) }\end{array}$ & 20 & 86.1 & 5.8 & 88 & 71 & 92 & 0.0001 \\
\hline $\begin{array}{c}\text { Delta HSS } \\
\text { (points) }\end{array}$ & 20 & 25.2 & 2.6 & 26 & 10 & 52 & 0.0001 \\
\hline $\begin{array}{c}\text { Relative delta } \\
\text { HSS (\%) }\end{array}$ & 20 & 46.9 & 7.4 & 42.3 & 13.5 & 140.5 & 0.5 \\
\hline
\end{tabular}

SD: standard deviation; SE: standard error, only for the deltas.

Source: Santa Casa, 2010

We observed that there was a significant increase in HSS score after surgery in the subgroup $\leq 65$ years, with a mean of 25.2 points $(\mathrm{p}=0.0001)$, which corresponded to a mean of $46.9 \%(p=0.0001)$.

Along general lines, our analysis showed that, independent of the age group, there was a significant increase in HSS score from before to after the operation.

Table 5 shows the mean, standard error (SE), median, minimum and maximum of the absolute change (delta) and relative change (delta \%) in HSS score, according to age subgroup and the descriptive level ( $p$ value) of the Mann-Whitney test.

We observed that there was no significant difference in the absolute delta $(p=0.24)$ or relative delta $(p=0.31)$ of the HSS score between the age groups.
Tabela 5 - Análise do delta do escore HSS segundo a faixa etária.

\begin{tabular}{c|c|c|c|c|c|c|c}
\hline HSS SCORE & $\mathbf{n}$ & Mean & SD/SE & Median & Minimum & Maximum & $\mathbf{p}$ value \\
\hline $\begin{array}{c}\text { Before } \\
\text { operation } \\
\text { (points) }\end{array}$ & 20 & 61.0 & 12.1 & 60 & 37 & 81 & \\
\hline $\begin{array}{c}\text { After operation } \\
\text { (points) }\end{array}$ & 20 & 86.1 & 5.8 & 88 & 71 & 92 & \\
\hline $\begin{array}{c}\text { Delta HSS } \\
\text { (points) }\end{array}$ & 20 & 25.2 & 2.6 & 26 & 10 & 52 & 0.0001 \\
\hline $\begin{array}{c}\text { Relative delta } \\
\text { HSS (\%) }\end{array}$ & 20 & 46.9 & 7.4 & 42.3 & 13.5 & 140.5 & 0.0001 \\
\hline
\end{tabular}

SD: standard deviation; SE: standard error, only for the deltas. Source: Santa Casa, 2010

\section{DISCUSSION}

In our series of patients, females predominated over males, which is concordant with the notion that osteoarthrosis preferentially affects females ${ }^{(10)}$.

Our study was motivated by the fact that Brazil is among the developing countries. It is a country of enormous dimensions with very heterogenous regions. The longevity of the Brazilian population is constantly increasing and therefore it becomes important to have implants of lower cost and reasonable durability, which demonstrates the relevance of our study. Robertsson et al ${ }^{(11)}$ conducted a study in Sweden and observed that $36 \%$ more patients will need total knee arthroplasty over the next 20 years. Total knee arthroplasty is considered to be a high-complexity surgical procedure of high cost and, for this reason, not all cities in Brazil have the capacity to carry out this procedure. Scott et al ${ }^{(12)}$ considered that the cost of the implant was the main factor causing difficulty in carrying out surgical procedures, thus corroborating our study. Our results might be of benefit for Brazilian municipalities in which this procedure is not performed.

In our evaluation according to age group, we did not find that the implant had greater durability among the more elderly population. In our view, patients who are more elderly would theoretically be more sedentary and hence, their implants would present less wear and greater durability. However, this was not seen in our study, and this was probably 
related to loss of follow-up among the more elderly patients due to natural death. On the other hand, Ritter $^{(13)}$ observed that the durability was greater among a population over the age of 70 years.

Our analysis evaluated the follow-up among patients who underwent arthroplasty using Brazilian implants, performed by a single surgical team. In our view, the evaluation with a single surgical team makes this study more relevant and reduces the possibility of bias.

Most revision procedures on total knee arthroplasty take place within the first five years ${ }^{(14,15)}$. For this reason, our results so far are satisfactory, within the clinical follow-up studied.

In the radiographic analysis, we had three cases in which we observed a radiolucent line without loosening of the implant, which were asymptomatic from a clinical point of view. These three patients had had 13, 7 and 5 years of clinical follow-up, respectively. The radiolucent line did not progress on the knee radiographs and all of these patients received an excellent score in the HSS system. They presented radiographic abnormalities of the tibial component, which according to Fuchs et $a l^{(16)}$ is the region most frequently affected, In the literature, it is emphasized that radioscopy is the best way to detect radiolucent lines ${ }^{(16)}$. This was perhaps the reason why we had low rates of abnormalities in imaging evaluations. We did not use radioscopy because we did not have this type of equipment available in our service at the start of this study.

The HSS evaluations were used in a blinded manner, in which a physician with a doctorate in orthopedics measured the scores before the operation, six months after the operation and every year thereafter. The evaluator's experience and routine use of the HSS score system were fundamentally important for the validity of the study $^{(17)}$.

In the HSS score system after the operation, our study reached a mean of 87 points. In comparison with the findings in the literature, we observed that our score system results were similar but that the mean length of follow-up for the comparison group was 15 years $^{(18)}$.

In our study, we only had four patients with a diagnosis of rheumatoid arthritis, all with five years of follow-up. One of these patients underwent bilateral total knee arthroplasty with an interval of four months between the two procedures. Two of these patients were classified as presenting excellent HSS scores and the other two were classified as presenting good HSS scores. In the literature, it has been reported that such patients present lower levels of daily activities and greater risk of infection ${ }^{(19,20)}$. Our sample of rheumatoid patients with HSS score classified as good was considered to be high $(50 \%)$, thus showing the greater attention that should be given to these patients.

The implants that were used preserved the posterior cruciate ligament (PCL). In our view, with a complete PCL, we preserved a greater amount of bone stock for future revision. Since our investigation is new within our setting, given that it evaluates Brazilian implants, revision of the knee arthroplasty should be taken into consideration. The PCL is the main stabilizer for the knee and, therefore, if this ligament is complete, it contributes towards enabling the knee to have proprioception that is closer to normality. Within the Brazilian literature, Villardi et al ${ }^{(21)}$ observed that the results were better among patients who underwent total knee arthroplasty with preservation of the PCL, from gait analysis.

In our study, all the patients underwent replacement of the patellar component. Studies have shown that the main complication is the patellofemoral joint. Therefore, since we were evaluating a Brazilian implant that had not previously been evaluated, we thought that it would be prudent to replace all the patellae ${ }^{(22)}$.

We found three cases of patellofemoral pain. One of these patients evolved with patellofemoral instability, and proximal and distal realignment were performed. The other two patients were treated conservatively (analgesic physiotherapy, stretching and muscle strengthening). These three patients were classified as presenting excellent HSS scores.

\section{CONCLUSION}

Total knee arthroplasty using an implant made in Brazil, performed by a trained and experienced team, has so far been shown to present satisfactory results in clinical follow-ups on patients with knee osteoarthrosis or rheumatoid arthritis. 


\section{REFERENCES}

1. Font-Rodriguez DE, Scuderi GR, Insall JN. Survivorship of cemented total knee arthroplasty. Clin Orthop Relat Res. 1997;(345):79-86.

2. Ritter MA. The Anatomical Graduated Component total knee replacement: a long-term evaluation with 20 -year survival analysis. J Bone Joint Surg $\mathrm{Br}$. 2009;91(6):745-9.

3. Ritter MA, Herbst SA, Keating EM, Faris PM, Meding JB. Long-term survival analysis of a posterior cruciate-retaining total condylar total knee arthroplasty. Clin Orthop Relat Res. 1994;(309):136-45.

4. Rand JA, Ilstrup DM. Survivorship analysis of total knee arthroplasty. Cumulative rates of survival of 9200 total knee arthroplasties. J Bone Joint Surg Am. 1991;73(3):397-409.

5. Insall JN, Kelly M. The total condylar prosthesis. Clin Orthop Relat Res. 1986;(205):43-8.

6. Gandhi R, Tsvetkov D, Davey JR, Mahomed NN. Survival and clinical function of cemented and uncemented prostheses in total knee replacement: a meta-analysis. J Bone Joint Surg Br. 2009;91(7):889-95.

7. Insall JN, Ranawat CS, Aglietti P, Shine J. A comparison of four models of total knee-replacement prostheses. J Bone Joint Surg Am. 1976;58(6):754-65.

8. Leach RE, Gregg T, Siber FJ. Weight-bearing radiography in osteoarthritis of the knee. Radiology. 1970;97(2):265-8.

9. Ewald FC. The Knee Society total knee arthroplasty roentgenographic evaluation and scoring system. Clin Orthop Relat Res. 1989;(248):9-12.

10. Barretto JM, Albuquerque RP, Oliveira PG, Malta M. Enxertia óssea em artroplastia primária do joelho: avaliação transoperatória. Rev Bras Ortop. 2006;41(10):399-404

11. Robertsson O, Dunbar MJ, Knutson K, Lidgren L. Past incidence and future demand for knee arthroplasty in Sweden: a report from the Swedish Knee Arthroplasty Register regarding the effect of past and future population changes on the number of arthroplasties performed. Acta Orthop Scand 2000;71(4):376-80.
12. Scott WN, Booth RE Jr, Dalury DF, Healy WL, Lonner JH. Efficiency and economics in joint arthroplasty. J Bone Joint Surg Am. 2009 ;91(Suppl 5):33-6.

13. Ritter MA. The Anatomical Graduated Component total knee replacement: a long-term evaluation with 20 -year survival analysis. J Bone Joint Surg Br. 2009;91(6):745-9.

14. Gioe TJ, Killeen KK, Grimm K, Mehle S, Scheltema K. Why are total knee replacements revised?: analysis of early revision in a community knee implant registry. Clin Orthop Relat Res. 2004;(428):100-6.

15. Sharkey PF, Hozack WJ, Rothman RH, Shastri S, Jacoby SM. Insall Award paper. Why are total knee arthroplasties failing today? Clin Orthop Relat Res. 2002;(404):7-13.

16. Fuchs R, Mattuella F, Rabello LT. Artroplastia total do joelho. Rev Bras Ortop. 2000;35(3): 94-101.

17. Albuquerque RP, Carvalho ACP, Giordano V, Djahjah MC, Amaral NP. Estudo comparativo entre incidências radiográficas para a osteoartrose do joelho. Acta Reumatol Port. 2009;34:380-7.

18. Ranawat CS, Flynn WF Jr, Saddler S, Hansraj KK, Maynard MJ. Long-term results of the total condylar knee arthroplasty. A 15-year survivorship study. Clin Orthop Relat Res. 1993;(286):94-102.

19. Mestriner LA, Filho JL. Artroplastia total do joelho em artrite reumatóide e osteoartrose. Rev Bras Ortop. 1993;28(4): 211-8.

20. Wilson MG, Kelley K, Thornhill TS. Infection as a complication of total kneereplacement arthroplasty. Risk factors and treatment in sixty-seven cases. J Bone Joint Surg Am. 1990;72(6):878-83.

21. Villardi AM, Turqueto LV, Franco JS, Gagy M, Silva PJG, Raptopoulos L, et al. Análise da marcha pós-artroplastia total do joelho com e sem prservação do ligamento cruzado posterior. Rev Bras Ortop. 2005;40(6):316-30.

22. Turqueto L, Villardi A, Leite ER, Palma IM, Tejada JV. Artroplastia total do joelho com e sem substituição da patela. Rev Bras Ortop. 1994;29(5):318-20. 